\title{
Entrevista com Kameron Steele ${ }^{1}$
}

Juliana MONTEIRO²

\section{Resumo}

Esta entrevista apresenta algumas questões referentes à relação entre a invisibilidade e a poesia na cena a partir do Método Suzuki de Treinamento do Ator, sob o ponto de vista do ator e diretor Kameron Steele ${ }^{3}$.

Palavras-chave: Método Suzuki de Treinamento do Ator, Invisibilidade na Cena, Orientalismo.

\begin{abstract}
This interview introduces some questions about the relationship between the invisibility and the poetry in performance, taking the Suzuki Method of Actor Training as a starting point under the point of view of the director and actor Kameron Steele.

Keywords: Suzuki Method of Actor Training, Invisibility in Performance, Orientalism.
\end{abstract}

Nota introdutória

Sistematizado pelo encenador Tadashi Suzuki e por sua companhia, a Suzuki Company of Toga (SCOT), para viabilizar seus objetivos estéticos, o Método Suzuki de Treinamento para o Ator constitui os códigos e princípios performáticos do grupo - são suas disciplinas de atuação, e, tiveram como ponto de partida, os fundamentos e os padrões de movimento da tradição teatral japonesa, especificamente do Kabuki e do Nô. Alternando movimentos lentos e rápidos, contínuos e em staccato e combinando um trabalho de corpo e voz na sua relação com o espaço, o treinamento compreende um circuito de 1 h3o de exercícios
1.

Kameron Steele, nascido em Duluth (EUA), é ator e diretor. BFA em Performance Studies: Northwestern University, MFA em Direção: CalArts. Trabalha com The South Wing/ALASUR. Em 1991, juntou-se à companhia de Tadashi Suzuki (SCOT) em Toga, onde, desde então, tem trabalhado como ator, assistente de direção, professor e tradutor, aparecendo em King Lear, Waiting for Romeo, Ivanov, Greetings from the Edge of the Earth and Dionysus. Entre 1998 e 2007 também trabalhou no Watermill Center, de Robert Wilson, aparecendo nas tournês das produções de Persephone, The Days Before, Woyzeck e Prometheus. Espetáculos como diretor: NYC-Mosheh: a videopera, Hanjo,Epona's Labyrnith, Saudade, (all at Arts Center), AOI! (Japan Society, PRELUDE Festival, undergroundzerofestival @PS122), Death in Vacant Lot! (Watermill; LMCC), HanjoRedux (CRS), The Bacchae (LIU). Internacional Hanjo (Teatro Degollado, Mexico; La Bellone, Belgium),Las Bacantes (Teatro Mendoza, Argentina), e Opium (STUK, Belgium; Monty, Antwerp; Brakke Grond, Amsterdam: cocriado com Arco Renz/Kobalt Works). CalArts - No Exit, Suddenly Last Summer, The Threepenny Opera.

2.

Professora efetiva - Curso de Teatro Universidade Federal de São João Del Rey (UFSJ). Bacharel em Artes Cênicas pela Unicamp, atriz e diretora. Mestre em Artes pela ECA/USP. Doutoranda em Artes da Cena pela Unicamp. E-mail: juclod@gmail.com

3.

Esta entrevista foi realizada no dia 31 de agosto de 2014 e gravada por Fabiano Lodi, em Toga Arts Park, Toyama, Japão, na sede da Suzuki Company of Toga (SCOT), durante o festival SCOT Summer Season 2014, promovido pelo grupo. 
pré-estabelecidos. Internacionalmente, passou a ser difundido no início dos anos de 1980 e é reconhecido, dentre outros, por seu rigoroso vocabulário físico, por solicitar o engajamento do ator a todo o momento, pelo alto grau de concentração e clareza que demanda e pela prontidão, sensibilidade e percepção que desperta.

Em algumas ocasiões, sua apropriação por artistas estrangeiros foi questionada; tanto nos termos de que talvez o "corpo ocidental" não se adequasse aos padrões propostos pelo método (Brandon, 1978), quanto nos termos de uma possível superficialidade num diálogo de natureza intercultural. Não há como negar que existam traços da cultura nipônica a permeá-lo. No entanto, é preciso ressaltar que tais indícios não podem ser tomados como definidores ou representantes do modo de ser de uma cultura ou excludentes de outra, como proposto por estudos orientalistas quando da criação de todo um imaginário e ideal referentes ao Oriente (Cox, 2003).

Outro aspecto, de extrema pertinência, é o fato de que o método está pautado na potencialização do corpo energético do ator. Por meio deste elemento, a apreensão do acontecimento teatral se dá por outros canais. Expandindo a discussão e lembrando que estamos no campo das artes, é na invisibilidade que o ato poético encontra sua eficácia.

Juliana Monteiro - Há 25 anos você treina e trabalha com o Método Suzuki. Como soube a respeito dele?

Kameron Steele - Eu li o livro de Suzuki, publicado em inglês - The way of acting [Suzuki, 1986], e fiquei impressionado por suas ideias. A ideia de que os seres humanos estão desconectados de seus corpos, mente e espírito naturais em virtude da civilização, da vida contemporânea, do uso de computadores... Acho que o que ele escreve no artigo Culture is the body - e que no livro foi chamado de Grammar of the feet é ainda mais pertinente nos dias atuais. Em todos os lugares as pessoas usam Iphone, Ipad... mesmo quando se vai jantar com alguém. Você não está com a pessoa. Penso que isso esteja extremo hoje em dia.

Esse foi meu primeiro encontro com ele, através de suas ideias. E por meio de um intercâmbio, em 1989, eu fui estudar na Universidade Waseda ${ }^{4}$. Quando estive lá, fui apresentado a ele e assisti ao Dionysus, sua versão para As bacantes, de Eurípedes. Até aquele momento, eu havia trabalhado como ator nos Estados Unidos, no colegial. Eu tinha 19 anos.

Nos EUA, muitos atores começam fazendo musicais; fazem
4.

Localizada em Tóquio, a Waseda é uma universidade particular, que prioriza a livre investigação. 
Bye, bye, Bertie, Fidler on the roof, Sound of music. Eu fiz todos estes. Meu treinamento era em teatro musical. Mas começou a se tornar monótono; era muito previsível. Acreditava que o teatro deveria fazer mais que isso. Então, eu assisti a Dionysus. Realmente, eu acreditava que o teatro deveria ter certa função social, não ser apenas entretenimento; tem que fazer as pessoas pensarem, fazer com que as pessoas pensem e descubram algo e não só assistir à mesma coisa que eles sabem o que será. Achava que o teatro deveria fazer as pessoas se questionarem, no lugar de terem uma resposta.

Ao ver o teatro de Suzuki, ele me encheu de perguntas. E com uma energia específica, que eu não tinha visto antes. Foi assim que eu entrei em contato com Suzuki.

$J M$ - Após todos esses anos nesse trabalho, como você vê seu caminho como ator hoje? Também em termos de energia, técnica, poesia e acerca da filosofia e dos conteúdos éticos com os quais o Método te coloca em contato.

KS - A ética é a moral do treinamento. O artista, qualquer artista, não só atores, tem sempre que trabalhar em direção ao que é desafiador, em direção ao que não pode fazer ou ao que é difícil.

Parte do problema nas artes, na atuação, é a influência que o capitalismo e o comercialismo tem sobre elas. Pois ao precisar vender algo, você o limita: tem que fazer com que tenha um nome, um formato, uma cor; uma imagem que a audiência possa facilmente compreender e consumir. Para o ator e para a audiência, isso é forçá-los a viver num tipo de produto fixado, com uma mentalidade produzida.

E a poesia existe para abrir a imaginação, para se ter uma energia diferente da que rege o dia-a-dia e que sustenta uma vida monótona. A poesia nos faz sentir mais vivos, nos faz ver as coisas de um jeito novo, um jeito mais profundo (preferencialmente) e mais vivo.

E o ator não tem que repetir só aquilo que ele sabe. Muitos atores pensam que são bons em algo... Então, "nós faremos tal coisa. Nós repetiremos isso e ganharemos dinheiro por fazê-lo". Cai-se nesse tipo de sistema, de mecanismo e acomodação e não nos forçamos a fazer algo novo. Talvez seja por isso que às vezes o teatro é ruim. As pessoas estão apenas repetindo as mesmas coisas, certas de que irão ser bem sucedidas.

E a ética é sempre um trabalho em direção a um desafio, a algum tipo de obstáculo. Tentamos superar desafios.

O treinamento [Suzuki] te dá obstáculos claros e técnica também. Mas neste trabalho, o que é mais importante que a técnica é que você está treinando sua vontade, sua mente, para 
somá-los ao seu processo criativo, para olhar para sua dificuldade e superá-la e não só permanecer num caminho confortável. Ele tenta treinar seu pensamento e como focar sua energia.

Voltando à sua pergunta, acho que a parte ética é ser sério a respeito disso, e concentrado. Porque fazer isso, ir em direção à dificuldade é difícil... Você se distrai; as pessoas tem um tipo de energia frívola, leve, casual. Dessa forma, você realmente não encontrará o obstáculo para atingir uma camada mais profunda do trabalho. E você precisa fazê-lo individualmente e como um grupo, no caso de uma companhia. Teatro é algo que tem que acontecer em grupo. Temos que estar focados em algo juntos. A ética é parte disso.

Como ator, é importante não ficar estagnado em seu próprio processo, mas realmente se abrir para o todo. Algo que me ajudou como ator foi começar a dirigir. Comecei a dirigir há 10 anos. De repente, compreendi melhor o que era o trabalho do ator. "Ah! Ok. Tenho que me preocupar com isso e com aquilo..." Como ator, tenho que estar ciente de que faço parte de algo maior.

É fácil para um ator agir como: "Ah, gosto que ela faça assim...." [parodiando big stars]. Parte disso vem da cultura em que eu cresci: o sistema das estrelas, todo mundo quer ser uma estrela, fundamentado no sistema stanislavskiano, etc.; uma cultura em que o individualismo é muito forte, mais do que em qualquer outro país...

$J M$ - Você trabalha em outras produções, além daquelas da SCOT, como ator e como diretor?

KS - Comecei a trabalhar com Suzuki em 1989 e permaneci até 1994. Em 1995 voltei aos EUA e trabalhei no Off Broadway, em espetáculos comerciais. Fiz algumas tragédias, Shakespeare, peças de Noel Coward.

Nesse período não trabalhei com Suzuki. Continuei treinando, mas queria voltar à minha cultura, ver o que estava acontecendo. Em 1998, comecei a trabalhar com Robert Wilson. Participei de quatro espetáculos dirigidos por ele. E o ajudei na construção do Watermill Center ${ }^{5}$ em Nova York, que é inspirado em Toga. Mantive contato com artistas e com o teatro japonês e praticamente só trabalhei com Bob. E não fiz mais espetáculos comerciais.

Em 2003, comecei a trabalhar como diretor, trabalhei bastante no México, Espanha, França, Nova York, Bélgica, Argentina. Viajei bastante, principalmente como diretor. Em 2008, eu voltei a Toga.

Quando eu comecei a dirigir, eu comecei a treinar os atores
5.

Fundado em 1992, este é um Laboratório de Performances, para jovens artistas com interesse em explorar novas ideias. 
e a ensinar o Método Suzuki a eles; Bob também me havia pedido isso junto aos atores que trabalhavam com ele.

$J M$ - Enxergo as cenas de Suzuki e Wilson, ou como eles as constroem, como pinturas. Você vê similaridades entre os dois diretores?

KS - Hum, talvez...Suzuki como um Rembrandt e Bob como um Magritte. Mas o trabalho deles é bastante diferente um do outro. As similaridades são especialmente em termos da relação física com o espaço.

$J M$ - Como a geometria do espaço se conecta ao corpo dos atores...

KS - Sim. O quão sensível ao espaço você tem que estar como ator. E isso o treino também te ajuda a desenvolver: a sensibilidade ao espaço.

Então, comecei a trabalhar com Bob e aos poucos voltei a trabalhar com Suzuki. Ele me chamou para voltar e em 2008 eu comecei a ensinar o Método aqui em Toga. Passo seis meses trabalhando para Suzuki e o resto do ano trabalho na Argentina e nos EUA.

$J M$ - Em seu processo de criação, você pensa na invisibilidade ou isso é algo que está implícito?

KS - Esta é uma ideia sobre a qual falo bastante em meu trabalho.... a ideia do movimento, da permanência; de que, enquanto se está na permanência, o movimento continua a acontecer...

Trabalho muito com atores americanos - da América do Sul, do Norte e Central. Em geral, o pensamento no Ocidente está focado no movimento, no som, no que se pode ouvir, no que se pode ver se movendo. Uma coisa que eu gosto, por exemplo, sobre a música japonesa... Um modo de se falar sobre ela é que as notas estão lá para estruturar o silêncio, assim as notas estão lá para criar o silêncio. Nesse mesmo sentido, gosto da ideia de que o movimento está ali para criar momentos de pausa.

Em geral, o teatro que tenho assistido está lotado e preocupado em estimular a audiência, pois pensam que a audiência tem muito estímulo e que se está competindo com computadores. Mas, o que de fato é preciso fazer é estimular a imaginação dela. Trabalhando com a ideia de pausa e silêncio... isso abre possibilidades de se imaginar o que ocorre no mundo invisível, inaudível. Trabalhar com estes dados é realmente importante para se engajar a imaginação. Mas, há um outro ingrediente com o qual se tem que trabalhar como um diretor: é a mise-en-scène, o que é bem diferente.

Mas penso que em geral não se tem muita consciência sobre a pausa e o silêncio; continua-se achando que é preciso dar 
muito estímulo à plateia. E o que ocorre é que, neste caso, ela se torna passiva com tudo isso. Ela não trabalha, não ajuda.

A plateia tem que ajudar a criar o evento; não cabe só ao ator, ao dramaturgo, ao cenógrafo fazê-lo; a plateia tem que ser ativa. Do contrário, é impossível ao teatro manter sua função social. Você sabe, todo o barulho está lá, te distraindo do mundo, te tirando de onde você realmente está e de pensar a respeito daquilo. É como o que Brecht disse sobre alienação... A plateia não pode se deixar levar por um tipo de fantasia. Ela tem que se lembrar que assiste a uma peça, que assiste ativamente a uma peça; que está atuando na questão que a peça lhe coloca, como um construtor de conhecimento.

É muito fácil também para um diretor fazer algo bonito, no qual a plateia vai se perder e esquecer o mundo. Penso que quando as peças de Bob não funcionam é porque isso acontece. Mas quando funcionam e tem uma crítica afiada... Quando ele dirige as peças de Heiner Müller. Hamlet machine é um grande exemplo disso.

E claro, Suzuki também sempre tem um plano altamente político para suas peças. Mesmo numa peça pequena como a de ontem ${ }^{6}$, você pensa sobre a família, sobre ficar velho, sobre um amor perdido. Tem uma ressonância maior.

$J M$ - Para finalizar, você gostaria de dizer algo mais?

KS - Acho que uma coisa é importante de se lembrar: mesmo sabendo que Suzuki é japonês e que o trabalho acontece aqui.... A razão pela qual o treinamento é importante é porque não é tão japonês. Quero dizer que o que de fato é valioso nele é que não está limitado à sensibilidade japonesa. $\mathrm{T}$ em um apelo mais amplo, universal e é com isso que Suzuki tem lidado por muitos anos; isso é de fato fundamental.... As coisas com as quais os atores tem de lidar, com que qualquer artista tem de lidar como cidadão do mundo... Não ficar preso à cidade; ir para longe da cidade e se concentrar profundamente em algo que possa ser útil a todos. Ir além dos conteúdos japoneses. É um grande risco... muitos veem o trabalho dele e acham que é japonês.

$J M$ - Como você disse, o fato de se entrar em contato com um outro, outra dificuldade, outro limite e possibilidades...

KS - Exato. É por isso que chamar isso de "japonês" é perigoso, porque assim que se nomeia algo - especialmente no ocidente, dizer: "Oh, essa é uma cultura um tanto quanto estranha, não tem a ver comigo"... Isso é orientalismo. É fácil colocar o trabalho [de Suzuki] nessa categoria cultural de "coisa japonesa estranha". E perde-se totalmente o ponto. Principalmente como ocidentais, escrevendo a respeito, é preciso estar atentos para não cair em orientalismos.
6.

Referindo-se à apresentação de The Origin of the Song Karatachi Nikki a que assistimos no dia anterior, no Shin Toga Sanbo Theatre na sede da SCOT. 


\section{REFERÊNCIAS}

BRANDON, James. Training at the Waseda Little Theatre: The Suzuki Method. The Drama Review, Vol. 22, No.4, December 1978. New York University Press.

COX, Rupert A. The Zen Arts. An Antropological Study of the Culture of Aesthetic Form in Japan. New Yoork: Routledge Curzon, 2003. SANTOS, Juliana Reis Monteiro dos. Quando técnica transborda em poesia: Tadashi Suzuki e suas disciplinas de atuação. Dissertação de Mestrado. ECA/USP, 2009.

SUZUKI, Tadashi. The Way of Acting: The Theatre Writings of Tadashi Suzuki. New York: Theatre Communications Group Inc., 1986. J. Thomas Rimer (Translator). 